\title{
IMMUNOALLERGIC DISORDERS IN THE ELDERLY
}

Martins-dos-Santos, Gonçalo ${ }^{1}$; Araújo, Miriam ${ }^{1}$; Prates, Sara ${ }^{1}$; Leiria-Pinto, Paula ${ }^{1}$

${ }^{1}$ Department of Immunoallergology, Centro Hospitalar Universitário de Lisboa Central Lisi on, Portugal

Corresponding author:

Gonçalo Martins dos Santos,

Address: Serviço de Imunoalergologia, Hospital de Du la Estefânia, Centro Hospitalar Universitário de Lisboa Central, EPE, Rua Jacinta Martu, 1 loy-045 Lisboa, Portugal

Telephone: +351213126653

Fax: +351213126654

E-mail: goncalommdsantos@gmail.com

ORCID: https://orcid.org/0000-0002-572f,_-7d 


\begin{abstract}
Although allergic diseases have become increasingly prevalent in the elderly, there are few data on this population. Through a retrospective analysis of the electronic medical records of patie its , ged 65 years and above followed in our Immunoallergology Unit, we aimed to char ill ize the immunoallergic diseases of the elderly. The most common disorders were respira: $x y$ diseases $(n=185 ; 50 \%)$, mucocutaneous diseases $(n=113 ; 31 \%)$, drug allergy $(n=31 ; 8 \%)$, fond ${ }^{\prime \prime}$.ergy $(n=9$; $2 \%)$, and anaphylaxis $(n=9 ; 2 \%)$. Use of specific immunotherapy was residual $(1=; 1 \%)$. There was an association between anaphylaxis and both, drug $(p=0.004)$ and $\mathrm{f} \odot \mathrm{od}$ ' $(b=) .013)$ allergies. Non-allergic rhinitis and bronchial asthma were more frequent $1 \mathrm{~h}$ tc.nales, and ACE inhibitors/ARB induced-angioedema in males. Recognizing the chara 'rist cs of immunoallergic diseases in the elderly and the specificities of this age group is nara `ount in providing these patients with the best possible care.
\end{abstract}

Key words: elderly, old-aged, allergy, immunoallergic, prevalc.'ce 


\section{LIST OF ABBREVIATIONS}

ACE - Angiotensin-converting-enzyme

ACO - Asthma-COPD overlap

ARB - Angiotensin II receptor blockers

CHULC - Centro Hospitalar Universitário de Lisboa Central

$\mathrm{CI}$ - Confidence interval

COPD - Chronic obstructive pulmonary

disease
DRESS - Drug reaction with eosinophilia and systemic symptoms

IAL - Immunoallergology

IgE - Immunoglobulin E

NSAID - Nonsteroidal anti-ı $\cdot f^{\prime}$ ammatory drug

\section{INTRODUCTION}

In recent years, the average life expectancy of the population has $b_{c} \vee \eta$ increasing, particularly in developed countries. The World Health Organization considars alderly people those over the age of 65 in developed countries, and those over the age o. $\oiiint$ liv $n g$ in developing countries ${ }^{1}$. Thus, the elderly population has increased over the past ferv years. In Portugal, 20.1\% of the population is 65 or older $^{2}, 19.4 \%$ is the percentage in Europe ${ }^{3}$. Th, diseases of this age group have become more frequent and complex, and allergic diso $\mathrm{a}^{\mathrm{f}} \boldsymbol{\rho}$ (such as respiratory and mucocutaneous diseases, drug hypersensitivity, and food allerg; ; aı no exception ${ }^{4,5}$. Although allergic conditions are often thought of as childhood disorders, hey often persist into older age and can occasionally make its initial appearance in the el $e^{r} !^{\circ}$. Besides, clinical manifestations may be less straightforward than in younger age grr ups, ilampering the recognition of the disease, and resulting in a more complicated differential di uglıus ${ }^{6}$. As most studies regarding immunoallergic disorders do not include the elderly popr1ai ${ }^{\circ}$, only limited data is available $e^{6,7}$ on its frequency and characteristics, making their maıı ge ment even more difficult.

\section{OBJECTIVE}

We aimed to charariris: the elderly population followed in our outpatient Immunoallergology (IAL) Unit regard: $n_{5}$. attention on thi part $^{+}$cular group of patients, with the ultimate goal of improving the care that is provided to thı $\eta$. I hus, we hope to contribute to a better understanding of the allergic diseases and their manc. remunt in this age group with numerous specificities.

\section{PETIODS}

Patient selection 
We performed a retrospective analysis of patients aged 65 years and older followed between 2009 and 2019 in the IAL outpatient Clinic at Centro Hospitalar Universitário de Lisboa Central (CHULC), in Portugal. Referral to our IAL Unit is done through the national Immunoalle so $^{\text {nogy }}$ network. A total of 31,758 patients attended our Unit between 2009 and 2019, of whic 1,721 $(5.4 \%)$ were elderly. Based on an estimated rhinitis prevalence of $50 \%$, in our popuatic n. v ith $5 \%$ error margin and a CI of $97 \%$, we obtained a sample size of 370 patients. Ranc mization was

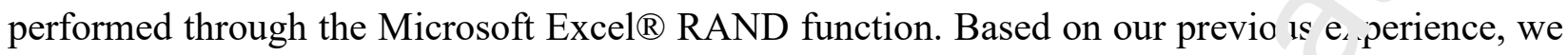
estimated to lose $25-30 \%$ of patients because some of the clinical records fror 1 the period between 2009 and 2014 were not accessible in electronic format, as this represents ${ }^{\prime} \cdot e_{\iota} \cdot n^{\prime}$ sition period from manual to electronic medical records in our Unit. Thereby, we incled a t total of 480 patients. Patients with incomplete $(n=1)$ or without filled electronic clinical rec $\left.{ }^{n} d s, n=109\right)$ were excluded and thus, a total of 370 patients were analysed.

\section{Data collection}

Data was collected through the manual review of the ele -'ronic medical records.

\section{Definitions}

For the analysis of the immunoallergic disenst., we obtained the diagnosis registered by the assistant physician in the clinical files. Resp1. ${ }^{\dagger}{ }^{\dagger}{ }^{r} y$ diseases, mucocutaneous diseases, drug allergy, food allergy, and other less frequent imm 1 'or llergic diseases were considered. Rhinitis, bronchial asthma, asthma-chronic obstructive pul nonary disease overlap (ACO), and Churg-Strauss syndrome were included in the $\mathrm{r} \epsilon$ spir tory diseases subgroup. In the mucocutaneous diseases subgroup we included angioeder a : 'thout urticaria, urticaria with or without angioedema, contact dermatitis, and atopic dermatitis. : ne diagnosis of food allergy was made through the medical history, tests for sensitization, $\cdot \mathbf{r}$ in cases of doubt, oral food challenges. The diagnosis of drug hypersensitivity was tase ${ }^{1}$ or the clinical history and, when appropriate, skin prick tests, intradermal tests, and drug ,rovucation tests. All patients whose drug allergy was excluded underwent drug provocation te ts.

\section{Statistical ana.', ${ }^{\prime}$;}

The statictı. ${ }^{-1}$ analysis was made with IBM SPSS Statistics version 26 for Windows. The variables gen ${ }^{\lambda}$ er, a se immunoallergic diseases, and sensitization profile were analysed.

$\because \because n_{\mathrm{C}}$ rmal distribution of continuous variables was tested using the Kolmogorov-Smirnov test and $\mathrm{t} y$ visual analysis of the histogram. The non-parametric variables assessed were expressed as median and interquartile range. A comparison between the categorical variables was made using 
the chi-squared test or the Fisher's exact test with Bonferroni corrections, as appropriate. All statistical tests were bilateral and with a 5\% significance level.

\section{Data protection}

The study protocol was reviewed and approved by the local ethics committees.

\section{RESULTS}

\section{Characterization of population}

The median (P25-P75) age of the patients in our sample was 75 71-81) years. There was a predominance of the female gender $(n=261 ; 71 \%)$. For most mmun allergic diseases, there was no statistically significant difference in gender distribution; th or were, however, some exceptions, namely non-allergic rhinitis and bronchial asthma, $1 \%$, re fr squent among females, and ACE inhibitors/ARB induced-angioedema, more commor in malcs (Table I).

The frequency of different groups of immunoallers: r. common diseases were respiratory diseases $(n=1\{5,5) \%)$, mucocutaneous diseases $(n=113 ; 31 \%)$, drug allergy $(n=31 ; 8 \%)$, food allergy $(n=9 \cdot 2 \%$, , and anaphylaxis $(n=9 ; 2 \%)$. Immunoallergic diseases were excluded in $16 \%(n=61)$ of pai ${ }^{\cdot} n^{\dagger} ;$.

\section{Respiratory diseases}

Respiratory diseases were the $r_{10}+$ + common disorders affecting these elderly patients $(\mathrm{n}=185$; $50 \%)$, with rhinitis $(n=169 ; 46 \%$, and bronchial asthma $(n=73 ; 20 \%)$ being the most frequent diagnoses. The concomitant $\mathrm{d}_{\mathrm{n}}$ ranosis of rhinitis and bronchial asthma was present in $31 \%(\mathrm{n}=58)$ of these individuals. T.e su nsi ization profile for aeroallergens was assessed in 162 patients (88\%), through skin prick test ana or specific serum IgE: $57 \%(n=92)$ were sensitized to aeroallergens, as shown in Table II. iens itization to a single aeroallergen group was found in $68 \%(n=63)$ : either house dust mite, $(.=32 ; 51 \%)$ or pollen $(n=31 ; 49 \%)$. All sensitized patients to pet or mold allergens, were a' $c$ o sensitized to other allergen groups.

Specific in $m_{\iota}$ notherapy to inhalant allergens was being administered to only one patient in our sample. $\sim^{\prime}$ is patient had allergic rhinitis and was taking subcutaneous immunotherapy for grass poli :

C. nsiu ring the patients with rhinitis, the sensitization profile was obtained in $93 \%(n=157)$, with $58 \%(n=91)$ classified as allergic rhinitis. Among the 66 patients with non-allergic rhinitis (42\%), senile rhinitis was diagnosed in $15 \%(\mathrm{n}=10)$. Concomitant diagnosis of sinusitis was found in $7 \%$ $(n=11)$ of rhinitis patients, of which $64 \%(n=7)$ also had nasal polyposis. Nasal surgery was 
performed in $57 \%(\mathrm{n}=4)$ of the patients with rhinosinusitis and nasal polyposis, and the remaining $(n=3 ; 43 \%)$ were managed with medical therapy, namely topical nasal glucocorticoids.

In what concerns asthma, most of the patients in our sample had disease onset after the a se $\iota$ 40 $(76 \% ; n=39)$. Asthma onset before the age of 40 was recorded in 12 cases $(24 \%)$. Info 1 II tiun on the age of asthma onset was missing from the electronic medical records of the ${ }^{\top} \eta_{\text {tuining }} 22$ patients. The sensitization profile of the patients with bronchial asthma was eralu ${ }^{+} \mathrm{zd}$ in $82 \%$ $(n=60)$, and sensitization to aeroallergens was found in $63 \%$ of them $(n=38)$.

Allergic asthma was more common among patients with disease onset betc $\cdot 2$ age of $40(80 \%$; $\mathrm{n}=8$ of 10 patients with skin prick tests or specific serum $\operatorname{IgE}$ ) than am ${ }^{n n}$, atients with asthma onset after the age of $40\left(52 \% ; n=16\right.$ of 31 patients with skin prick tes $r_{i}$ specific serum IgE). ACO was diagnosed in $8 \%(n=6)$.

None of these patients were managed with biological therapies.

Other respiratory diseases were rare. Churg-Strauss syndrome , ' 75 diagnosed in one patient $(0.3 \%)$, well controlled with daily oral $5 \mathrm{mg}$ of equivalen $\mathrm{p}$ edn solone; another one $(0.3 \%)$ had nonsteroidal anti-inflammatory drugs (NSAID)-exacerbatt. ${ }^{1}$ respiratory disease.

\section{Mucocutaneous diseases}

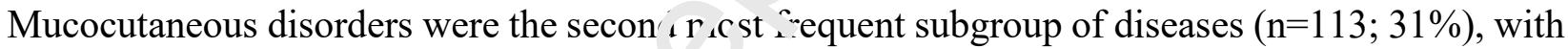
the most common being angioedema withuut urticaria $(n=55 ; 15 \%)$, urticaria $(n=46 ; 12 \%)$, and contact dermatitis $(n=12 ; 3 \%)$.

The aetiology of angioedema r 11 ut urticaria, could not be identified in $53 \%(n=29)$ of the affected patients, thus classified as . .aving idiopathic angioedema. In $42 \%(n=23)$, it was attributed to angiotensin-converting-enzy re (ACE) inhibitors and in $2 \%(n=1)$ to angiotensin II receptor blockers (ARB). From the ' sh sroup of patients with ACE inhibitors-induced angioedema, an ARB was tried as alternativ: in $5 \%(n=9)$, all with tolerance. $\mathrm{C} 1$ inhibitor deficiency was found in $4 \%$ $(n=2)$ of the patient wi $h$ angioedema; a haematological neoplasm was diagnosed in one of them (acquired deficie $\mathrm{ac}_{;}$; and the other one did not complete the investigation.

Urticaria was diaz iosed in 46 patients, most of them with chronic urticaria $(74 \% ; n=34)$. Chronic urticaria $\mathrm{w}$ is $\mathrm{C}^{\prime} \cdot$ ' $s$ ssified as spontaneous in $82 \%(\mathrm{n}=28)$ of the cases and as inducible in the remaining $\left(18 \%\right.$; $\left.r_{-}-\right)$. Patients with chronic spontaneous urticaria were mostly managed with oral H1 anti. $\therefore$ tal $\because$ le agents, taken once a day $(n=18 ; 64 \%)$, twice a day $(n=8 ; 29 \%)$, or four times a day ( $.7 \%$. $7 \%$. Because of lack of response to antihistamines, one patient received treatment with cyclowporin, which had to be stopped after one year due to haematological toxicity. This patient was then treated with oral $\mathrm{H} 1$ antihistamine agents taken four times a day and mirtazapine, with a good response and no adverse effects. Treatment with omalizumab had not been started in any 
patient in our sample. Among the patients with inducible urticaria, dermographism was diagnosed in $83 \%(n=5)$, and cold-induced urticaria in $17 \%(n=1)$; all of them were well controlled with oral H1 antihistamine agents taken twice a day $(n=3 ; 50 \%)$, three times a day $(n=1 ; 17 \%)$, or as $n$ 'eded $(n=2 ; 33 \%)$. Acute urticaria was diagnosed in $26 \%(n=12)$ of urticaria patients, being i $\lambda_{1}$, athic and self-limited in all cases.

Twelve patients (3\%) had a diagnosis of contact dermatitis. During the etiologinal 1. estigation, epicutaneous tests were carried out. Several agents were identified, with nickei $n=4 ; 33 \%$ ) and caines $(n=4 ; 33 \%)$ being the most common ones.

In our sample no patient was diagnosed with atopic dermatitis.

\section{Drug allergy}

Investigation of suspected drug hypersensitivity was carried c $\lambda$ t in $\angle: \%(n=78)$ of patients (Table III). The diagnosis was excluded in $50 \%(\mathrm{n}=39), 14 \%(\mathrm{n}=1$ 1) , 1.1 not complete the investigation,

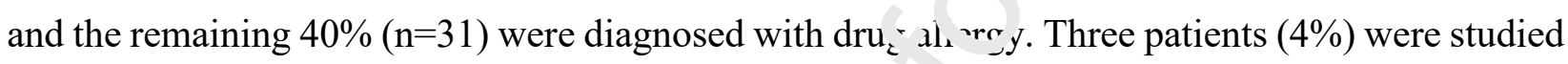
for more than one drug allergy.

Mild mucocutaneous symptoms were the most fre, ${ }^{\prime} e^{r}$.t clinical manifestation in patients with confirmed drug allergy $(n=24 ; 77 \%)$. In $16 \%$, $\mathrm{p}$ itients $(\mathrm{n}=5)$, anaphylaxis was the clinical presentation (local anaesthetic, iodinated contrası ' gent, inhaled budesonide, NSAID, and gliptin) and one patient $(3 \%)$ had a severe cutaın 1 , adverse reaction, namely drug reaction with eosinophilia and systemic symptoms (DF Fs $s$ ) due to allopurinol.

In the patients who did not complete he nvestigation $(n=11 ; 14 \%)$ and in those in whom drug allergy was excluded $(n=39 ; 50 \%)$. rild mucocutaneous symptoms were the most frequent manifestation ( $\mathrm{n}=8 ; 73 \%$ and $\mathrm{n}=2, f ; 1,7 \%$, respectively). In both groups, unspecific symptoms were the second most frequent $c^{1}$ aical presentation $(n=3 ; 27 \%$ and $n=10 ; 26 \%$, respectively) and no severe reactions were regi, $⿻$, a

\section{Food allergy}

Food allergy was nosed in $2 \%(n=9)$ of the patients (Table IV). The most implicated food group was the crust ${ }^{\wedge}$ ceaı. $3(n=6 ; 67 \%)$; a concomitant sensitization to house dust mite was found in four of these pitic.ts. The two patients with allergy to fresh fruits also had allergy to nuts, with sensitiz $\therefore$ ㄱ ${ }^{\circ}$ lipid transfer protein, both with a concomitant sensitization to pollens. There was no $\because \operatorname{qg}_{1} \sim$ sis of milk, eggs, cereals, or profilins allergy. Most patients presented mild 1. wanc itaneous reactions $(n=6 ; 67 \%)$. However, there were 3 cases of anaphylaxis $(33 \%)$, all due to nuıs. 


\section{Other less frequent immunoallergic diseases}

Hymenoptera venom allergy was confirmed in 2 patients (1\%). Both presented with anaphylactic reaction, one after a bee sting and the other one after a wasp sting. Specific immunother ıpy vas administered only to the former since the latter refused it. Hymenoptera venom rilc. oy was excluded in another patient whose symptoms were attributed to a toxic reaction afte: buing stung by a swarm of about 200 bees.

Common variable immunodeficiency was diagnosed in one patient $(0.3 \%)$, co $\iota r 0 i^{\prime} \mathrm{d}$ with regular administration of subcutaneous immunoglobulin.

There was no record of latex allergy in this sample.

\section{$\underline{\text { Associations between immunoallergic diseases }}$}

Allergic rhinitis had a statistically significant association with allergic bronchial asthma $(p<0.001)$ and food allergy $(p=0.012)$.

Non-allergic rhinitis had a statistically significant associainn with non-allergic bronchial asthma $(p<0.001)$.

Confirmed drug allergy $(p=0.004)$ and food alle $g^{\prime}(\eta=0.013)$ were significantly associated with anaphylaxis.

No additional statistically significant associai $n n^{c}$ were found between the other analysed disorders.

\section{DISCUSSION}

In our outpatient Unit, the ${ }^{-}$derly population accounted for a minority of the patients observed. However, we expect that a 1 i creasing number of older people will be referred to allergy clinics as the current younger alle ${ }_{2}$ ic ,horts age and are joined by those developing allergies in later life . $^{7}$ More targeted studiec $a_{2}$ ' needed to understand if this expected increase is only due to the ageing of the general popu'atir $\mathrm{n}$, or if immunoallergic diseases are also becoming more prevalent and recognized in the $s^{d}$, rly.

Respiratory $d_{1} \cdot a \cdot$ es were the most common immunoallergic disorders affecting our sample, with rhinitis ar. bronchial asthma being the most frequent. In line with previously published data, we found $s$ er s zation to aeroallergens in $57 \%$ of these patients, with a clear predominance of house dust $\eta_{1}{ }^{+}$e and pollen allergens ${ }^{4,8-10}$. Pollen sensitization varies worldwide depending on species pivaiulce in each region. In our sample, similarly to the available data in our country in younger ages, the most commonly involved pollen allergens were wall pellitory, grass, and olive tree ${ }^{10}$. However, while grass pollen represents the most common pollen sensitization in the general population ${ }^{10}$, sensitization to wall pellitory and grass pollen were equally common in our elderly 
sample. Most patients were sensitized only to a single group of aeroallergens - either house dust mites or pollens - and less common sensitizations, like pet epithelia or molds, were only found in polysensitized patients.

Bronchial asthma was one of the more common disorders, alerting to the importance $\Omega 1$ ' ${ }^{\top}$ inning strategies to deal with the particular problems presented by these patients: difficulty vain therapy administration due to their less dexterity, reduced self-management capability assnclian $d$ with less disease awareness, and frequent cognitive impairment ${ }^{11}$. In congruence with prev or $\mathrm{s}$ studies ${ }^{12,13}$, while asthma diagnosed before the age of 40 was more often allergic, late on at a sthma was more often non-allergic. Moreover, whereas atopic disease usually begins 1 . childhood and early adulthood, non-allergic asthma may be related to cumulative exp sure to irritants such as occupational exposures and smoking and thereby becomes evident only ' ${ }^{\prime}$ ter in life ${ }^{13}$.

In our sample, some patients were diagnosed with ACO in concor lanı e with its greater prevalence in older patients ${ }^{14}$. A substantial percentage of elderly patierts haa : simultaneous diagnosis of allergic rhinitis and allergic bronchial asthma, with a statis ${ }^{*} \eta_{1}$, significant association between these diseases, similarly to what is found in younger $r^{- \text {ti }^{n+s}}{ }^{5}$. Non-allergic rhinitis was also a common diagnosis, a result we could expect since $i^{\wedge}$ is a frequent condition in this age ${ }^{4}$. We have also found a significant association between non-al erg1 . rhinitis and non-allergic asthma, in line with previously published data ${ }^{16}$. The diagnosis o 1 r , c al allergic rhinitis was not taken into account because nasal provocation tests were not impic nented in the routine diagnostic approach. Thus, we admit that some patients may have been "vror gly diagnosed with non-allergic rhinitis, which is one of the limitations of our study.

Angioedema without urticaria was th : $m_{1}$ st common mucocutaneous disorder. The majority of patients was diagnosed with idiopat lic a ngioedema, which is in line with published data in younger cohorts $^{17}$. ACE inhibitors/ARB- $n$. 'ced angioedema represented the second most common cause of angioedema without urticaria in our sample, with a higher frequency compared to other published studies ${ }^{17,18}$. Most nai ${ }^{\circ}$ ts had this clinical presentation in response to an ACE inhibitor, and a considerable per zen ' $\mathrm{ge}$ tolerated an ARB as an alternative drug. This is a relevant finding given the well-establi i ed venefits of this drug class in cardiovascular and renal diseases, when compared to the avc ilab e alternatives, namely calcium channel blockers. More studies are needed to support our re, $\mathrm{u}^{1}$.

Similarly to $c^{\text {ther }}$ ublished studies ${ }^{6}$, urticaria, especially chronic spontaneous urticaria, was quite common $\varepsilon$ na well managed with oral $\mathrm{H} 1$ antihistamine agents. The patient who remained uncontr ${ }^{\prime} \cdot \mathrm{d}$ uespite treatment with oral $\mathrm{H} 1$ antihistamine agents taken four times a day, and thus trea $\cdot{ }^{1} \mathrm{w}^{* 1}+1$ cyclosporin, was diagnosed in 2014 . By that time, the available guidelines advocated

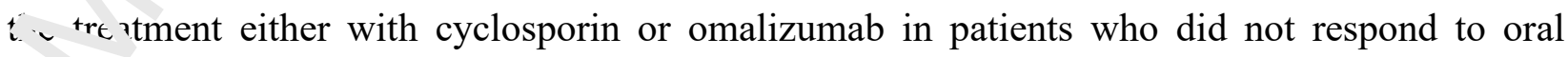
antihıstamines ${ }^{19}$. In this patient, the choice of mirtazapine after cyclosporin discontinuation was based on the presence of depressive manifestations and on published reports of its efficacy in several skin disorders, including chronic urticaria ${ }^{20,21}$. It had a good efficacy and tolerance showing 
that, in some cases, alternative drugs for the treatment of urticaria failing to respond to $\mathrm{H} 1$ antihistamine agents might be useful and more cost-effective than the therapy advocated by the guidelines. This fact can be especially relevant in the context of limited financial resou as for health care. As for idiopathic angioedema, it is particularly important in the elderly to ex $c^{1} 1 u_{i}$ other disorders that may be the cause of chronic urticaria, before assuming a diagncsis of thronic spontaneous urticaria ${ }^{6,22}$.

Contact dermatitis was not very frequent in our sample and, in line with another or olished study in elderly patients, the most implicated allergens were nickel and caine. ${ }^{23}$. No patient was diagnosed with atopic dermatitis, as expected from its lower prevalence roıpared to younger patients ${ }^{6}$.

Drug allergy is particularly important in this age group consicirins its polypharmacy and, therefore, the higher probability of developing a drug allergy ${ }^{24} \cdot r \cdot \mathrm{n}$ t 2 other hand, polypharmacy may make the identification of the culprit drug more difficult and cu nplex, especially when it is an essential drug which cannot be easily withdrawn. In our ${ }^{4} \mathbf{c}_{j}$; the most implicated drugs were NSAIDs, beta-lactam antibiotics, and allopurinol, in 91 a ${ }^{\circ}$ ent with other published data ${ }^{6,24}$. Although mild mucocutaneous symptoms were the most common presentation, anaphylaxis had a considerable frequency in our sample. Moreover, v e fc und a statistically significant association between confirmed drug allergy and anaphylaxis $1^{+} 1^{\sim}$ crucial to perform an early diagnosis and a correct approach to anaphylaxis cases, miınııng new episodes that could have drastic consequences in a high-risk population for $:$ fata outcome ${ }^{25,26}$.

It is important to underline that we were a'jl to exclude drug allergy in half of the patients with suspected drug hypersensitivity. The nosi often suspected and excluded drugs were beta-lactam and macrolide antibiotics, local ar aesthetics, and iodinated contrast agents. Exclusion of drug allergy has a huge importance ar, 1, slows these elderly patients to receive the most effective and less toxic drug and, in the case of a.tibiotic agents, contributes to improve the resistance profile of many bacterial microorganicm. ${ }^{27}$.

Food allergy had a rela. ve , low frequency in this aged population, mimicking other published studies $^{6}$. The most imn: - ated allergens were crustaceans and nuts. Although mild mucocutaneous symptoms were th $\mathrm{m}$ sst common clinical presentation, we found a statistically significant association betw - n food allergy and anaphylaxis, which underlines the critical importance of making a ccrrec diagnosis to avoid a second episode that could be fatal in such a fragile population $"$. ' significant association between food allergy and allergic rhinitis was also found. This as $\backsim$ ' $\mathrm{ql}_{1}$ on may be due to cross-reactivity between house dust mites and crustaceans (housedus....ite - ustaceans syndrome) or pollens and vegetable foods (pollen-food allergy syndrome) ${ }^{28}$. . , $\mathbf{x}_{\mathbf{L}}$ ected, there were no cases of allergy to milk or egg, the most common food allergies in paedıutric patients and with a natural tendency for resolution ${ }^{29,30}$.

Only two patients were receiving specific immunotherapy (one to grass pollen and one to bee venom), in agreement with the previously published data referring to low use of this resource in 
the elderly for reasons of efficacy and safety ${ }^{31,32}$. However, recent studies ${ }^{31}$ support the use of specific immunotherapy in this population. We expect that its application in the elderly may increase in the near future, with beneficial effects on symptom control and quality of life.

For most immunoallergic disorders, we did not find any statistically significant differenr es '-etween genders. However, the frequency of non-allergic rhinitis and bronchial asthma $w$ 's iigher in females, as previously published ${ }^{33}$. ACE inhibitors/ARB-induced angioedema was mi”e common in males, in line with previously reported data ${ }^{18}$ and against what was found in vo in ger ages ${ }^{17,34}$.

\section{Limitations}

Some limitations can be identified in our study. Because this constitutes a single-centre study, the results should not be generalized. Being a retrospective study, the su hushed associations between disorders could not be definitive since many confounding faci is could not be controlled. Moreover, the analysed data were obtained from electronic mu tical records, and possibly resulted from subjective interpretation from each patient's assi tai $t$ pl ysician. As mentioned earlier, the diagnosis of local allergic rhinitis was not considered anc, therefore, some misdiagnosis of nonallergic rhinitis was possibly made. Hypersensitivit u chemotherapy drugs was not observed in our series because the approach to those patients unally performed at the Chemotherapy Day Unit and not at the Outpatient Unit.

\section{CONCLUSION}

The most frequent immunoallergis $a_{1 z}$ iders of the elderly patients evaluated in our IAL outpatient Unit are respiratory diseases, $112 \mathrm{~m}$,ly allergic and non-allergic rhinitis and bronchial asthma. Patients with respiratory a."ergies are mainly sensitized to house dust mites or pollen. Mucocutaneous diseases are also common, especially angioedema, both idiopathic and ACE inhibitors/ARB induce 1 , a ${ }^{\prime} \mathrm{d}$. hronic spontaneous urticaria. Drug allergy represents an important diagnosis in a polym edicaied population. We were able to exclude it, however, in half of the cases. Food allergy is $1 f_{\text {us }}$ unnmon. We found an association between anaphylaxis and both drug and food allergies.

In summar , it iv crucial to consider the specificities of this population, whose referral to the IAL consultation, 'vill likely increase in the upcoming years. Particular attention is required if we are to proride $\mathrm{t}^{\prime} \mathrm{e} n$ with the best quality care and, ultimately, improve their quality of life. More tailored studic ? luigeting this population group are needed to support our results. 


\section{CONFLICTS OF INTEREST}

The authors declare the absence of economic or other types of conflicts of interest.

\section{FUNDING}

The study did not receive funding.

\section{REFERENCES}

1. World Health Organization. Accessed https://www.who.int/healthinfo/survey/ageingdefnolder/er/

Fr bruary $\quad 1, \quad 2020$.

2. Instituto Nacional de Estatística. Ac es ea February 1, 2020. https://ine.pt/xportal/xmain?xpid=INE\&xpgid=ine_. at. $^{\prime}$

3. Eurostat. Accessed February 1, 2020. https://ec.e's.npa.eu/eurostat/statistics-explained/

4. Ventura MT, D'Amato A, Giannini M, Carre'ca A, Tummolo RA, Buquicchio R. Incidence of allergic diseases in an elderly populatic... nunopharmacology and Immunotoxicology. 2010;32(1):165-170. doi:10.3109/089230ากตับ213735

5. Valdés CJ, Tewfik MA. Rhinosinusitis ına Allergies in Elderly Patients. Clinics in Geriatric Medicine. 2018;34(2):217-231. doi $\cdot 1$ Ł 10 16/j.cger.2018.01.009

6. Cardona V, Guilarte M, Lueng , O. Labrador-Horrillo M, Sala-Cunill A, Garriga T. Allergic diseases in the elderly. Clin Tra, ${ }^{\circ}$. Allergy. 2011;1(1):11. doi:10.1186/2045-7022-1-11

7. Gray NJ, Redshaw EL, Isaacs _, Tarzi MD, Smith HE, Frew AJ. Allergy in the elderly: A case note review of referrals $、$ an adult allergy clinic. Clin Exp Allergy. 2018;48(9):1238-1241. doi:10.1111/cea.1317?

8. Huss K, Naumanr PL, iAason PJ, et al. Asthma severity, atopic status, allergen exposure, and quality of life ir elde. ly persons. Annals of Allergy, Asthma \& Immunology. 2001;86(5):524-

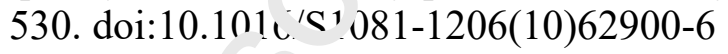

9. Liccardi G, Paiui G, Berra A, et al. Allergy in urban elderly population living in Campania region (Su,th :rn Italy). A multicenter study. Eur Ann Allergy Clin Immunol. 2016;48(4):5.

10. Burhach GJ, Heinzerling LM, Edenharter G, et al. GA2LEN skin test study II: clinical rel $V n_{1}$, of inhalant allergen sensitizations in Europe. Allergy. 2009;64(10):1507-1515. i. $\cdot 1$ v.1111/j.1398-9995.2009.02089.x

11. Tndo Bom A, Mota Pinto A. Allergic respiratory diseases in the elderly. Respiratory Medicine. 2009;103(11):1614-1622. doi:10.1016/j.rmed.2009.06.003 
12. M. Amelink, S. B. de Nijs, J. C. de Groot, et al. Three phenotypes of adult-onset asthma. Allergy. 2013;68:674-680. doi:10.1111/all.12136

13. Pakkasela J, Ilmarinen P, Honkamäki J, et al. Age-specific incidence of allergic a' a' nonallergic asthma. BMC Pulm Med. 2020;20(1):9. doi:10.1186/s12890-019-1040-2

14. Senthilselvan A, Beach J. Characteristics of asthma and COPD overlap syndrome ( ${ }^{\wedge}$ _OS ) in the Canadian population. Journal of Asthma. 2019;56(1):1:29-1137. doi:10.1080/02770903.2018.1531997

15. Togias A, Gergen PJ, Hu JW, et al. Rhinitis in children and adole cen s with asthma: Ubiquitous, difficult to control, and associated with asthma outcomes. $I_{\wedge}$ " $/ \mathrm{ergy}$ Clin Immunol. 2019;143(3):1003-1011.e10. doi:10.1016/j.jaci.2018.07.041

16. Bousquet J, Khaltaev N, Cruz AA, et al. Allergic Rhinitis and its 'mpact on Asthma (ARIA) 2008*: ARIA: 2008 Update. Allergy. 2008;63(68): if 1f. doi:10.1111/j.13989995.2007.01620.x

17. Malbrán E, Romero DF, Juri MC, Larrauri BJ, Malbró' A A. Epidemiology of angioedema without wheals in an allergy and immunology center. $\Lambda$ L $ר I N A$. 2015;75(5):4.

18. Alharbi FF, Kholod AAV, Souverein PC, et al. The 11. nact of age and sex on the reporting of cough and angioedema with renin-angiotensin vstem inhibitors: a case/noncase study in VigiBase. Fundam Clin Pharmacol. F ibli ined online September 5, 2017. doi:10.1111/fcp. 12313

19. Zuberbier T, Aberer W, Asero R, et al. The AACI/GA2LEN/EDF/WAO Guideline for the definition, classification, diagnosis, and ran: gement of urticaria: the 2013 revision and update. Allergy. 2014;69:868-887. doi:10.111/1/.11.'313

20. Bigatà X, Sais G, Soler F. Seve e cl ronic urticaria: Response to mirtazapine. J Am Acad Dermatol. 2005;53(5):916-917. uo1 i v.1016/j.jaad.2005.05.040

21. Eskeland S, Halvorsen JA, T $\mathrm{An}_{4} \sim \mathrm{L}$. Antidepressants have Anti-inflammatory Effects that may be Relevant to Dermatology: ^ Systematic Review. Acta Derm Venereol. 2017;97:897-905. doi:10.2340/00015555- ᄂ, 2

22. Dreyfus DH. Diffeienn. 1 J Jiagnosis of Chronic Urticaria and Angioedema Based on Molecular Biology, Pharmac $\log _{y}$, and Proteomics. Immunology and Allergy Clinics of North America. 2017;37(1):201·_ ¿15. Aoi:10.1016/j.iac.2016.08.010

23. Balato A, B I? $\sim$ N, Di Costanzo L, Ayala F. Contact sensitization in the elderly. Clinics in Dermatolog, 'źv11;29(1):24-30. doi:10.1016/j.clindermatol.2010.07.003

24. Ventur $11 \times$ T, Boni E, Cecere R, et al. Importance of hypersensitivity in adverse reactions to drugs in the elderly. Clin Mol Allergy. 2018;16(1):7. doi:10.1186/s12948-018-0083-x

25. N.ric: S, Dölle-Bierke S, Francuzik W, et al. Anaphylaxis in Elderly Patients-Data From the Flopean Anaphylaxis Registry. Front Immunol. 2019;10:750. Ini:10.3389/fimmu.2019.00750 
26. Ventura MT, Scichilone N, Gelardi M, Patella V, Ridolo E. Management of allergic disease in the elderly: key considerations, recommendations and emerging therapies. Expert Review of Clinical Immunology. 2015;11(11):1219-1228. doi:10.1586/1744666X.2015.1081564

27. Jimenez-Rodriguez TW, Blanca-Lopez N, Ruano-Zaragoza M, et al. Allergological L'tudy of 565 Elderly Patients Previously Labeled as Allergic to Penicillins. J Asthr ia '1lergy. 2019; Volume 12:421-435. doi:10.2147/JAA.S232787

28. Wise SK, Lin SY, Toskala E, et al. International Consensus Statement ('. Allergy and Rhinology: Allergic Rhinitis: ICAR: Allergic Rhinitis. Int Forum '1lergy Rhinol. 2018;8(2):108-352. doi:10.1002/alr.22073

29. Iweala OI, Choudhary SK, Commins SP. Food Allergy. C …r Fastroenterol Rep. 2018;20(5):17. doi:10.1007/s11894-018-0624-y

30. Kim JH. Clinical and Laboratory Predictors of Egg Allergy Re 1 ly tion in Children. Allergy Asthma Immunol Res. 2019;11(4):446. doi:10.4168/aair.2010 11. ‘446

31. Bożek A, Kołodziejczyk K, Kozłowska R, Canonica GW Evidence of the efficacy and safety of house dust mite subcutaneous immunotherapy $\mathrm{i} \cdot \mathrm{c}$ ' aurly allergic rhinitis patients: a randomized, double-blind placebo-controlled tr. ${ }^{\top}$. Clin Transl Allergy. 2017;7(1):43. doi:10.1186/s13601-017-0180-9

32. Roberts G, Pfaar O, Akdis CA, et al. EAACI Gu. teli ıes on Allergen Immunotherapy: Allergic rhinoconjunctivitis. Allergy. 2018;73(4):765-־y, doi:10.1111/all.13317

33. Baptist AP, Hamad A, Patel MR. Special chair iges in treatment and self-management of older women with asthma. Annals of Alle. ry, Asthma \& Immunology. 2014;113(2):125-130. doi:10.1016/j.anai.2014.05.013

34. Malde B, Regalado J, Greenberger PA. Investigation of angioedema associated with the use of angiotensin-converting enzyme inhlvitors and angiotensin receptor blockers. Annals of Allergy, Asthma \& Immunology. 2007:9 ‘'1).57-63. doi:10.1016/S1081-1206(10)60860-5 


\section{TABLES}

Table I: Gender distribution of the main immunoallergic disorders $(n=370)$. ACE - angiotensin-convertingenzyme; ARB - angiotensin II receptor blockers.

\begin{tabular}{|c|c|c|c|}
\hline DISORDER & $\begin{array}{c}\text { FEMALE } \\
\mathrm{n}(\%)\end{array}$ & $\begin{array}{c}\text { MALE } \\
\mathrm{n}(\%)\end{array}$ & $p$ va ue ${ }^{k}$ \\
\hline Rhinitis & $131(50)$ & $38(35)$ & ?07 \\
\hline Allergic & $68(26)$ & $23(21)$ & 0.313 \\
\hline Non-allergic & $54(21)$ & $12(11)$ & 0.027 \\
\hline Sensitization not assessed & $9(3)$ & $3(3)$ & \\
\hline Bronchial asthma & $61(23)$ & $12(11)$ & 0.006 \\
\hline Allergic & $32(12)$ & 6 (5) & 0.051 \\
\hline Non-allergic & $17(7)$ & $5(5)$ & 0.475 \\
\hline Sensitization not assessed & $12(5)$ & $(1)$ & \\
\hline Acute urticaria & $9(3)$ & $3(3)$ & 1.000 \\
\hline Chronic urticaria & $26(10)$ & $8(7)$ & 0.426 \\
\hline Spontaneous & $20(8)$ & $8(7)$ & 0.915 \\
\hline Inducible & $6(2)$ & $0(0)$ & 0.186 \\
\hline Contact dermatitis & $\left.11^{\prime}+\right)$ & $1(1)$ & 0.193 \\
\hline Angioedema & 30 (1: & $25(23)$ & 0.005 \\
\hline Idiopathic & li (1) & $11(10)$ & 0.297 \\
\hline $\mathrm{ACE} / \mathrm{ARB}$ & $11(4)$ & $13(12)$ & 0.006 \\
\hline C1 deficiency & $1(0)$ & $1(1)$ & 0.503 \\
\hline Drug allergy & $55(22) \#$ & $23(21)$ & 0.995 \\
\hline Confirmed & $22(8)$ & $9(8)$ & 0.816 \\
\hline Excluded & $27(10)$ & $12(11)$ & 0.889 \\
\hline Evaluation not comple $ə C$ & $9(3)$ & $2(2)$ & 0.519 \\
\hline Food allergy & $4(2)$ & $5(5)$ & 0.131 \\
\hline Hymenoptera venom a "rgy & $1(0)$ & $1(1)$ & 0.503 \\
\hline Anaphylaxis & $7(3)$ & $2(2)$ & 1.000 \\
\hline Total of patier ts & $261(71)$ & 109 (29) & \\
\hline
\end{tabular}

* level of sis nifi ance $<0.05$

\# In thr`e rem.dle patients, a hypersensitivity reaction was confirmed to one drug and excluded to anotheı $>n f$ 
Table II: Characterization of the sensitization profile of aeroallergens in patients with respiratory disorders $(\mathrm{n}=162)$. Weed mix extract contains: plantago, artemisia, salsola, and chenopodium.

\begin{tabular}{cc}
\hline $\begin{array}{c}\text { AEROALLERGEN } \\
\text { SENSITIZATION }\end{array}$ & $\begin{array}{c}\text { TOTAL } \\
\mathrm{n}(\%)\end{array}$ \\
\hline $\begin{array}{c}\text { House dust mite } \\
\text { Pollen }\end{array}$ & $\mathbf{5 9 ( 3 6 )}$ \\
Wall pellitory & $\mathbf{5 5}(\mathbf{3 4})$ \\
Grass & $27(17)$ \\
Olive tree & $26(16)$ \\
Weed mix & $21(13)$ \\
Plane tree & $19(12)$ \\
Birch tree & $14(9)$ \\
Pet epithelium & 1()$)$ \\
Cat dander & $\mathbf{1 2}(\mathbf{d}$, \\
Dog dander & $11(/)$ \\
Fungi & $\mathbf{7 ( 4 )}$ \\
Negative & $\mathbf{3 ( 2 )}$ \\
Total of patients & $\mathbf{7 0 ( 4 3 )}$ \\
\hline
\end{tabular}


Table III: Characterization of the patients with a completed drug allergy evaluation $(n=70)$. Note: Only two patients with suspected ACE inhibitors/ARB hypersensitivity were included in this table, both with a maculopapular rash, since bradykinin-mediated symptoms were not considered hereby. Some patif at were evaluated for more than one suspected drug hypersensitivity. ACE - angiotensin-converting-enz: $m_{1} \cdot \mathrm{ARB}$ - angiotensin II receptor blockers; NSAIDs - nonsteroidal anti-inflammatory drugs

\begin{tabular}{|c|c|c|c|}
\hline DRUG & $\begin{array}{c}\text { SUSPECTED } \\
\mathrm{n}(\%)\end{array}$ & $\begin{array}{c}\text { EXCLUDED } \\
\mathrm{n}(\%)\end{array}$ & $\begin{array}{c}\text { CONEIF MED } \\
\eta(\%)\end{array}$ \\
\hline Analgesics & $17(24)$ & $3(8)$ & $1 \sim(45)$ \\
\hline NSAIDs & $11(65)$ & $0(0)$ & $11(79)$ \\
\hline Metamizole & $2(12)$ & $0(0)$ & $2(14)$ \\
\hline Paracetamol & $4(24)$ & $3(100)$ & $1(7)$ \\
\hline Antibiotics & $33(47)$ & $25(64)$ & $8(26)$ \\
\hline Beta-lactam & $26(79)$ & $20(80)$ & $6(75)$ \\
\hline Macrolides & $5(15)$ & $416)$ & $1(13)$ \\
\hline Sulphonamides & $1(3)$ & c'v, & $1(13)$ \\
\hline Metronidazole & $1(3)$ & $1,4)$ & $0(0)$ \\
\hline Cardiovascular & $7(10)$ & $5(13)$ & $2(6)$ \\
\hline Antiplatelet agents & $1(14)$ & $0(0)$ & $1(50)$ \\
\hline Gliptins & $1(14)$ & $0(0)$ & $1(50)$ \\
\hline ACE inhibitors/ARB & $2(29)$ & $2(40)$ & $0(0)$ \\
\hline Beta-blockers & $1(1$ & $1(20)$ & $0(0)$ \\
\hline Calcium channel blockers & 14 & $1(20)$ & $0(0)$ \\
\hline Amiodarone & $1(1,1)$ & $1(20)$ & $0(0)$ \\
\hline Anaesthetics & $J())$ & $5(13)$ & $1(3)$ \\
\hline Local & $(83)$ & $4(80)$ & $1(100)$ \\
\hline General & $1(17)$ & $1(20)$ & $0(0 \%)$ \\
\hline Others & $16(23)$ & $8(21)$ & $8(26)$ \\
\hline Allopurinol & $6(38)$ & $1(13)$ & $5(63)$ \\
\hline Iodinated contrast agents & $5(31)$ & $4(50)$ & $1(13)$ \\
\hline Inhaled budesonide & $1(6)$ & $0(0)$ & $1(13)$ \\
\hline Mydriatic ocular ( ruy. & $1(6)$ & $0(0)$ & $1(13)$ \\
\hline B12 vitamin & $1(6)$ & $1(13)$ & $0(0)$ \\
\hline Prednisolone & $1(6)$ & $1(13)$ & $0(0)$ \\
\hline Iodopovide ae & $1(6)$ & $1(13)$ & $0(0)$ \\
\hline Total of patients & $70(100)$ & $39(56)$ & $31(44)$ \\
\hline
\end{tabular}


Table IV: Characterization of the sensitization profile of patients with food allergy $(n=9)$.

\begin{tabular}{lc}
\hline $\begin{array}{r}\text { FOOD ALLERGEN } \\
\text { SENSITIZATION }\end{array}$ & $\begin{array}{c}\text { TOTAL } \\
\mathrm{n}(\%)\end{array}$ \\
\hline Crustaceans & $6(67 \%)$ \\
Nuts & $3(33 \%)$ \\
Fresh fruits & $2(22 \%)$ \\
Fish & $2(22 \%)$ \\
Molluses & $2(22 \%)$ \\
Legumes & $1(11 \%)$ \\
Total of patients & 9
\end{tabular}

\section{FIGURES}

Figure 1: Most common immunoallergic r'isorucrs $(n=370)$ 